\title{
Sesquiterpenes from the Fruiting Bodies of Ramaria formosa and Their Human Neutrophil Elastase Inhibitory Activity
}

\author{
Kwan-Chul Kim, ${ }^{a, b, \#}$ Ik-Soo Lee, ${ }^{c, \#}$ Ick-Dong Yoo, ${ }^{b}$ and Byung-Jo Ha*,a \\ ${ }^{a}$ Department of Public Health, Graduate School of Science, Eulji University; Seongnam 461-832, Republic of Korea: \\ ${ }^{b}$ Innoskin Co., Ltd., BVC 209, Korea Research Institute of Bioscience and Biotechnology; Daejeon 305-806, Republic \\ of Korea: and ${ }^{c} K M$-Based Herbal Drug Development Group, Herbal Medicine Research Division, Korea Institute of \\ Oriental Medicine; Daejeon 305-811, Republic of Korea.
}

Received January 16, 2015; accepted April 1, 2015

Two new sesquiterpene derivatives (1 and 2), ramarin $A$ (1) and ramarin $B$ (2), together with three known compounds (3-5) were isolated from the fruiting bodies of Ramaria formosa. The structures of the two sesquiterpenes were established by extensive spectroscopic studies and chemical evidence. The inhibitory activity of the isolated compounds (1-5) against human neutrophil elastase (HNE) was evaluated in vitro. All compounds tested inhibited HNE by $35-30 \%$ at the highest concentration used $(100 \mu \mathrm{M})$, whereas the positive control, epigallocatechin gallate (EGCG), exhibited $60 \%$ inhibition at $100 \mu \mathrm{M}$.

Key words Ramaria formosa; Gomphaceae; sesquiterpene; human neutrophil elastase

Human neutrophil elastase (HNE), a serine protease found primarily in the azurophilic granules of neutrophils, has broad substrate specificity and can cleave not only elastin but also other extracellular matrix (ECM) proteins, such as collagen, fibronectin, laminin, and proteoglycans.) With aging, skin elasticity is decreased significantly by elastase activity, resulting in skin sagging and wrinkling. ${ }^{2)}$ Thus, developing pharmacological inhibitors of HNE might provide a therapeutic approach for preventing skin sagging and wrinkling in aging.

Many species of mushrooms have been used in folk medicine around the world for thousands of years. They produce various classes of secondary metabolites, many of which possess interesting biological activities and have the potential to be developed as therapeutic agents. ${ }^{3-5}$ ) Thus, mushrooms have been the focus of much attention in the search for specific pharmacologically significant compounds.

Ramaria formosa (PERS.) QuéL. is a coral fungus of the genus Ramaria in the family Gomphaceae, found primarily in Europe and North America. Previous studies revealed that the crude extract of $R$. formosa exhibited antimicrobial, anti-oxidant, and antitumor activities. ${ }^{6,7)}$ Cellulase activity was also detected in a culture of $R$. formosa. ${ }^{8)}$ Recently, a novel ribonuclease purified from $R$. formosa was reported to exhibit human immunodeficiency virus (HIV)-1 reverse transcriptase inhibitory activity. ${ }^{9)}$ However, there is no reported study of the secondary metabolites of this mushroom.

In searching for novel HNE inhibitors from higher fungi, we found that an ethyl acetate (EtOAc)-soluble fraction of the methanol $(\mathrm{MeOH})$ extract of the fruiting bodies of $R$. formosa had considerable HNE-inhibitory activity $\left(\mathrm{IC}_{50}=40.6 \mu \mathrm{g} / \mathrm{mL}\right)$. Further studies on this fraction resulted in the isolation of two new sesquiterpene derivatives (1 and 2), together with three known compounds (3-5). This report describes the isolation and structural determination of these sesquiterpene derivatives, and the characterization of their inhibitory effects against HNE.

\footnotetext{
${ }^{\#}$ These authors contributed equally to this work.

* To whom correspondence should be addressed. e-mail: bjha@eulji.ac.kr
}

\section{Results and Discussion}

$\mathrm{MeOH}$ extract of the fruiting bodies of $R$. formosa was suspended in $\mathrm{H}_{2} \mathrm{O}$ and partitioned successively with $n$-hexane, EtOAc, and $n-\mathrm{BuOH}$. The EtOAc-soluble fraction, which inhibited HNE activity significantly, was subjected to a series of chromatographic procedures, leading to the isolation of two new sesquiterpene derivatives ( $\mathbf{1}$ and $\mathbf{2}$ ), together with three known compounds (3-5) (Fig. 1). The three known compounds were identified as nambinone A (3) ${ }^{10}{ }^{1}$ axinysone A (4), ${ }^{11)}$ and ent-aristolone $(5)^{12)}$ and by comparing their physicochemical and spectral data with those in the literature.

Compound 1 was obtained as a colorless oil with the molecular formula $\mathrm{C}_{15} \mathrm{H}_{22} \mathrm{O}_{3}$, as established by high resolutionelectron ionization-mass spectrum (HR-EI-MS), based on a molecular ion peak at $\mathrm{m} / \mathrm{z} 250.1567[\mathrm{M}]^{+}$. The EI-MS of $\mathbf{1}$ showed a parent peak at $\mathrm{m} / \mathrm{z} 250$ and characteristic fragment

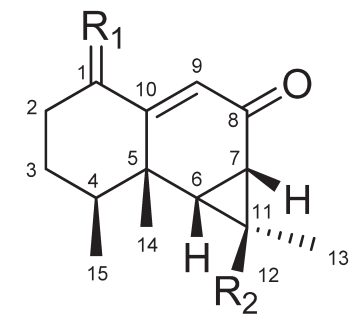

$\begin{array}{ccc} & \mathrm{R}_{1} & \mathrm{R}_{2} \\ 1 & \alpha \mathrm{OH}, \beta \mathrm{H} & \mathrm{CH}_{2} \mathrm{OH} \\ 2 & \mathrm{H}_{2} & \mathrm{CH}_{2} \mathrm{OH} \\ 3 & \alpha \mathrm{H}, \beta \mathrm{OH} & \mathrm{CH}_{2} \mathrm{OH} \\ 4 & \alpha \mathrm{OH}, \beta \mathrm{H} & \mathrm{CH}_{3} \\ \mathbf{5} & \mathrm{H}_{2} & \mathrm{CH}_{3}\end{array}$

Fig. 1. Chemical Structures of $\mathbf{1}-\mathbf{5}$ Isolated from the Fruiting Bodies of $R$. formosa 
Table 1. ${ }^{1} \mathrm{H}-(300 \mathrm{MHz})$ and ${ }^{13} \mathrm{C}-(75 \mathrm{MHz})$ NMR Data of Compounds $\mathbf{1}$ and $\mathbf{2}$ in MeOD

\begin{tabular}{|c|c|c|c|c|}
\hline \multirow{2}{*}{$\mathrm{C}$} & \multicolumn{2}{|r|}{1} & \multicolumn{2}{|r|}{2} \\
\hline & $\delta_{\mathrm{C}}$ & $\delta_{\mathrm{H}}(J$ in $\mathrm{Hz})$ & $\delta_{\mathrm{C}}$ & $\delta_{\mathrm{H}}(J$ in $\mathrm{Hz})$ \\
\hline 1 & $69.7 \mathrm{~d}$ & $4.38 \mathrm{dd}(12.0,5.2)$ & $31.8 \mathrm{t}$ & $\begin{array}{l}\text { ax: } 2.56 \text { ddd }(13.4,12.2,3.4), \\
\text { eq: } 2.32 \text { ddd }(13.4,3.6,1.8)\end{array}$ \\
\hline 2 & $36.3 \mathrm{t}$ & $\begin{array}{c}\mathrm{ax}^{a)}: 1.40 \text { dddd }(13.5,12.0,12.0,5.2) \\
\mathrm{eq}^{b)}: 2.10 \mathrm{~m}\end{array}$ & $34.5 \mathrm{t}$ & $\begin{array}{c}\text { ax: } 1.86 \text { dddd }(13.4,12.2,12.2,3.4), \\
\text { eq: } 1.42 \mathrm{~m}\end{array}$ \\
\hline 3 & $29.5 \mathrm{t}$ & $\begin{array}{c}\text { ax: } 1.48 \text { dddd }(13.4,13.0,12.2,3.2) \\
\text { eq: } 1.62 \mathrm{~m}\end{array}$ & $27.4 \mathrm{t}$ & $\begin{array}{c}\text { ax: } 1.58 \text { dddd }(13.4,12.2,12.2,3.4) \text {, } \\
\text { eq: } 1.50 \mathrm{~m}\end{array}$ \\
\hline 4 & $39.8 \mathrm{~d}$ & $1.85 \mathrm{dqd}(12.2,6.8,3.6)$ & $40.2 \mathrm{~d}$ & $1.88 \mathrm{dqd}(12.2,6.5,3.4)$ \\
\hline 5 & $40.6 \mathrm{~s}$ & & $40.7 \mathrm{~s}$ & \\
\hline 6 & $37.0 \mathrm{~d}$ & $1.65 \mathrm{~d}(8.0)$ & $36.5 \mathrm{~d}$ & $1.66 \mathrm{~d}(8.0)$ \\
\hline 7 & $32.3 \mathrm{~d}$ & $1.83 \mathrm{~d}(8.0)$ & $32.7 \mathrm{~d}$ & $1.83 \mathrm{~d}(8.0)$ \\
\hline 8 & $199.2 \mathrm{~s}$ & & $199.1 \mathrm{~s}$ & \\
\hline 9 & $121.3 \mathrm{~d}$ & 6.19 brs & $125.0 \mathrm{~d}$ & 5.74 brs \\
\hline 10 & $173.3 \mathrm{~s}$ & & $172.4 \mathrm{~s}$ & \\
\hline 11 & $31.0 \mathrm{~s}$ & & $31.8 \mathrm{~s}$ & \\
\hline 12 & $71.2 \mathrm{t}$ & $3.42 \mathrm{~d}(11.6), 3.32 \mathrm{~d}(11.6)$ & $71.2 \mathrm{t}$ & $3.43 \mathrm{~d}(11.6), 3.36 \mathrm{~d}(11.6)$ \\
\hline 13 & $12.5 \mathrm{q}$ & $1.23 \mathrm{~s}$ & $12.7 \mathrm{q}$ & $1.23 \mathrm{~s}$ \\
\hline 14 & $24.0 \mathrm{q}$ & $1.24 \mathrm{~s}$ & $23.3 \mathrm{q}$ & $1.27 \mathrm{~s}$ \\
\hline 15 & $16.2 \mathrm{q}$ & $1.10 \mathrm{~d}(6.8)$ & $16.6 \mathrm{q}$ & $1.10 \mathrm{~d}(6.8)$ \\
\hline
\end{tabular}

ions at $m / z 232\left(\left[\mathrm{M}-\mathrm{H}_{2} \mathrm{O}\right]^{+}\right)$and $217\left(\left[\mathrm{M}-\mathrm{H}_{2} \mathrm{O}-\mathrm{CH}_{3}\right]^{+}\right)$. The UV absorption maxima at $239 \mathrm{~nm}$ and the IR absorption band at $1665 \mathrm{~cm}^{-1}$ suggested the presence of a conjugated keto group, which was supported by the presence of a carbon resonance at $\delta_{\mathrm{C}} 199.2$ in the ${ }^{13} \mathrm{C}-\mathrm{NMR}$ spectrum. The ${ }^{1} \mathrm{H}-\mathrm{NMR}$ spectrum of 1 displayed the characteristic signals of an olefinic proton at $\delta_{\mathrm{H}} 6.19(1 \mathrm{H}, \mathrm{brs})$, a hydroxymethine proton at $\delta_{\mathrm{H}} 4.38(1 \mathrm{H}, \mathrm{dd}, J=12.0,5.2 \mathrm{~Hz})$, a pair of hydroxymethylene protons at $\delta_{\mathrm{H}} 3.42$ and $3.32(2 \mathrm{H}$, each d, $J=11.6 \mathrm{~Hz})$, two tertiary methyls at $\delta_{\mathrm{H}} 1.23$ and 1.24 (each $3 \mathrm{H}, \mathrm{s}$ ), and a secondary methyl at $\delta_{\mathrm{H}} 1.10(3 \mathrm{H}, \mathrm{d}, J=6.8 \mathrm{~Hz})($ Table 1$)$. The ${ }^{13} \mathrm{C}-\mathrm{NMR}$ spectrum, combined with the distortionless enhancement by polarization transfer (DEPT) data, revealed 15 carbon signals including a carbonyl carbon at $\delta_{\mathrm{C}} 199.2$, olefinic carbons at $\delta_{\mathrm{C}} 173.3$ and 121.3 , a hydroxymethine at $\delta_{\mathrm{C}} 69.7$, a hydroxymethylene at $\delta_{\mathrm{C}} 71.2$, and three methyls at $\delta_{\mathrm{C}} 24.0,16.2$, and 12.5 (Table 1). These spectroscopic data suggested 1 to be an aristolane-type sesquiterpene, in comparison with reported analogs. ${ }^{10-12)}$ Additionally, the ${ }^{1} \mathrm{H}-$ and ${ }^{13} \mathrm{C}-\mathrm{NMR}$ data of $\mathbf{1}$ were very similar to those of axinysone A (4), except for the resonances of a hydroxymethylene unit $\left(\delta_{\mathrm{H}} 3.42\right.$ and $3.32 ; \delta_{\mathrm{C}}$ $71.2)$ instead of a methyl group at C-12 $\left(\delta_{\mathrm{H}} 1.21 ; \delta_{\mathrm{C}} 29.7\right)$ in 4, suggesting that the C-12 methyl group of 4 was replaced by a hydroxymethylene group in $\mathbf{1}$. This was supported by the ${ }^{13} \mathrm{C}-\mathrm{NMR}$ chemical shift of $\mathrm{C}-11\left(\delta_{\mathrm{C}} 31.0\right)$, as well as analysis of the heteronuclear multiple bond connectivity (HMBC) spectrum (Fig. 2A). The HMBC correlations H-6/C-7, C-8, C-9 and H-7/C-6, C-8, C-9, C-10 confirmed that a cyclopropane moiety was connected to C-6 and C-7. The attachment of a hydroxymethylene group at $\mathrm{C}-11$ was deduced from the HMBC cross-peaks of $\mathrm{H}-12$ with $\mathrm{C}-6, \mathrm{C}-7, \mathrm{C}-11$, and $\mathrm{C}-13$. The relative configuration of $\mathbf{1}$ was determined on the basis of the nuclear Overhauser effect spectroscopy (NOESY) experiment (Fig. 2B) and a comparison with that of axinysone A (4). The $\beta$-configuratuons of the methyl groups at $\mathrm{C}-14$ and $\mathrm{C}-15$ were deduced from the nuclear Overhauser effect (NOE) correlations $\mathrm{Me}-14 / \mathrm{H}-3 \mathrm{ax}$ and $\mathrm{H}-4 \mathrm{ax} / \mathrm{H}-2 \mathrm{ax}$, respectively.
The NOE correlations H-6/Me-14 and H-4/Me-13 indicated an $\alpha$-configuratuon of the cyclopropane. Finally, the NOE correlations $\mathrm{H}-1 / \mathrm{H}-3 \mathrm{ax}, \mathrm{Me}-14$ lead to the assignment of an $\alpha$-configuratuon of the hydroxy group at $\mathrm{C}-1$, as found in 4 . The relative configuration of $\mathbf{1}$ was assigned as being identical to that of $\mathbf{4}$ on the basis of the NOE correlations. The absolute configuration of 1 was assumed to be the same as that of entaristolone series, possessing the $4 S, 5 S, 6 R, 7 S$ configuration, from the positive sign of its specific rotation, $[\alpha]_{D}^{25}+180^{\circ}(c$ $0.1, \mathrm{MeOH}$ ), and its co-occurrence with $\mathbf{3}-\mathbf{5}$ that possess an ent-aristolone structure. ${ }^{10-12)}$ Thus, the structure of 1 was established as ent-1 $\alpha, 12$-dihydroxy- 9 -aristolen- 8 -one, and named ramarin $\mathrm{A}$.

Compound 2 was obtained as a colorless oil, and showed a molecular ion peak at $\mathrm{m} / \mathrm{z} 234.1622[\mathrm{M}]^{+}$in HR-EI-MS, corresponding to the molecular formula $\mathrm{C}_{15} \mathrm{H}_{22} \mathrm{O}_{2}$. The UV $\left(\lambda_{\max }=237 \mathrm{~nm}\right)$ and IR $\left(v_{\max }=1662 \mathrm{~cm}^{-1}\right)$ spectra of 2 were characteristic of a conjugated keto group. The ${ }^{1} \mathrm{H}-\mathrm{NMR}$ spectrum of $\mathbf{2}$ was very similar to that of ent-aristolone (5), with the appearance of two typical high-field doublets at $\delta_{\mathrm{H}} 1.66$ and 1.83 (each $1 \mathrm{H}, \mathrm{d}, J=8.0 \mathrm{~Hz}$ ) as well as a singlet olefinic proton at $\delta_{\mathrm{H}} 5.74$ (Table 1), suggesting that 2 had the same aristolane skeleton with a cyclopropane group. The difference in the ${ }^{1} \mathrm{H}-\mathrm{NMR}$ spectrum of $\mathbf{2}$ versus that of $\mathbf{5}$ was the appearance of signals at $\delta_{\mathrm{H}} 3.43$ and 3.36 (each $1 \mathrm{H}, \mathrm{d}$, $J=11.6 \mathrm{~Hz}$ ), assignable to hydroxymethylene protons instead of the 12-methyl protons in $\mathbf{5}$. Inspection of the ${ }^{13} \mathrm{C}-\mathrm{NMR}$ spectrum in comparison with $\mathbf{5}$ revealed a marked downfield shift of the C-11 signal $\left(\delta_{\mathrm{C}} 31.8\right)$ (Table 1), suggesting the presence of a hydroxymethylene group at C-11 in 2, further supported by the HMBC correlations of $\mathrm{H}-12$ with C-6, C-7, C-11, and C-13 (Fig. 2A). The relative configuration of 2 was deduced as being identical to that of $\mathbf{5}$ from the NOESY spectrum (Fig. 2B). Furthermore, the positive sign of its specific rotation, $[\alpha]_{\mathrm{D}}^{25}+93^{\circ}(c 0.1, \mathrm{MeOH})$, indicated that 2 possess an entaristolone structure, as found in $\mathbf{3 - 5}$. Thus, the structure of $\mathbf{2}$ was assigned as ent-12-hydroxy-9-aristolen-8-one, and named 
(A)

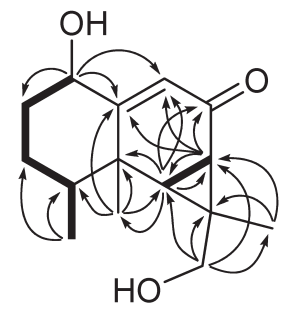

1

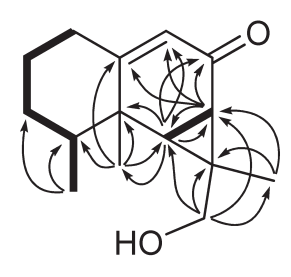

2 $\left[{ }^{1} \mathrm{H}-{ }^{1} \mathrm{H}\right.$ Cos

$\mathrm{HMBC}$

(B)

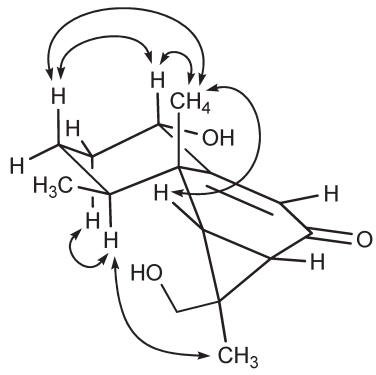

1

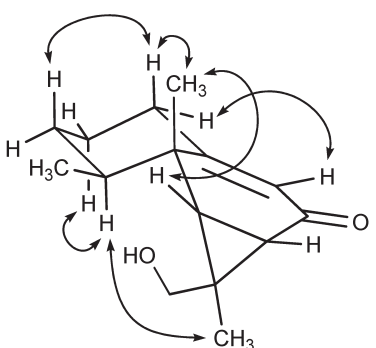

2

Fig. 2. Key ${ }^{1} \mathrm{H}-{ }^{1} \mathrm{H}$ COSY and $\operatorname{HMBC}(\mathrm{A})$ and Key NOE (B) Correlations of Compounds 1 and 2

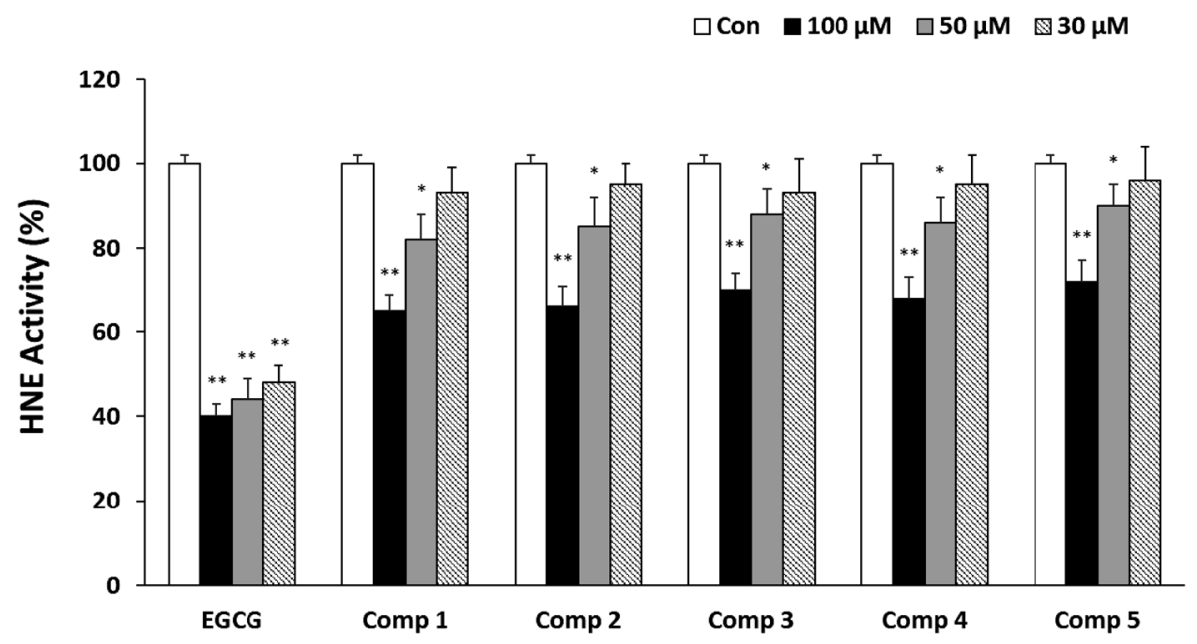

Fig. 3. HNE-Inhibitory Activity of 1-5 Isolated from the Fruiting Bodies of $R$. formosa

Results are expressed as the means \pm S.D. of three individual experiments. ${ }^{*} p<0.05,{ }^{*} p<0.01 v s$. Control.

ramarin $\mathrm{B}$.

The inhibitory activity of the isolated compounds (1-5) on $\mathrm{HNE}$ was evaluated in vitro according to a procedure described previously. ${ }^{13)}$ As shown in Fig. 3, HNE activity was reduced by treatment with $\mathbf{1}-\mathbf{5}$ in a dose-dependent manner. However, all tested compounds inhibited HNE by $35-30 \%$ at the highest concentration used $(100 \mu \mathrm{M})$, whereas the positive control, epigallocatechin gallate (EGCG), exhibited 60\% inhibition at $100 \mu \mathrm{M}$.

In the present study, we sought to identify effective HNEinhibiting agents from the fruiting bodies of $R$. formosa. We isolated two new (1 and 2) and three known aristolane sesquiterpenes (3-5). This is the first report of secondary metabolites from $R$. formosa. Aristolane-type sesquiterpenes have been reported to exhibit a number of biological activities, including cytotoxic, ${ }^{10,14)}$ antimicrobial, ${ }^{15)}$ and melanin synthesis inhibition ${ }^{16,17)}$ properties. Although the aristolane sesquiterpenes (1-5) isolated in this study did not showed marked inhibitory effects on HNE, their HNE-inhibitory properties are reported here for the first time.

\section{Experimental}

General Experimental Procedures Optical rotations were measured on a JASCO P-2000 digital polarimeter. UV 
and IR spectra were recorded on JASCO V-550 UV/Vis and JASCO 100 IR spectrometers, respectively. ${ }^{1} \mathrm{H}-(300 \mathrm{MHz})$ and ${ }^{13} \mathrm{C}$-NMR $(75 \mathrm{MHz})$ spectra were obtained using a Bruker DRX-300 spectrometer with TMS as an internal standard. Two dimensional (2D)-NMR experiments (correlation spectroscopy (COSY), HMBC, and NOESY) were run on a Bruker Avance 500 NMR spectrometer. HR-EI-MS and EI-MS were recorded on a Hewlett-Packard 5989B mass spectrometer. Column chromatography was performed using silica gel (70-230 mesh and 230-400 mesh, Merck) and YMC-gel ODS-A (12 nm, S-75 $\mu \mathrm{m}, \mathrm{YMC})$. Thin-layer chromatography (TLC) was performed on pre-coated silica gel $60 \mathrm{~F}_{254}(0.25 \mathrm{~mm}$, Merck) and RP- $18 \mathrm{~F}_{254 \mathrm{~s}}$ plates $(0.25 \mathrm{~mm}$, Merck). Spots were detected by UV light $(254 \mathrm{~nm})$ and spraying with $10 \% \mathrm{H}_{2} \mathrm{SO}_{4}$ followed by heating. Preparative HPLC was performed on a Gilson TRILUTION system with a 321 pump and a UV/Vis 151 detector, and a GX-271 liquid handler (Gilson, Inc.), using a YMC-pack Pro $\mathrm{C}_{18}(250 \times 10 \mathrm{~mm}$, i.d.) column.

Mushroom Material Fruiting bodies of $R$. formosa were collected at Mt. Jeoksang, Jeollabukdo, Korea in August 2013 and identified by Prof. KiHwan Bae, Chungnam National University, Republic of Korea. A voucher specimen (CNU-982) was deposited in the herbarium at the College of Pharmacy, Chungnam National University, Republic of Korea.

Extraction and Isolation Dried fruiting bodies of $R$. formosa $(350 \mathrm{~g})$ were extracted with $\mathrm{MeOH}(3 \times 8 \mathrm{~L})$ at room temperature for seven days, filtered, and concentrated to yield a $\mathrm{MeOH}$ extract $(22 \mathrm{~g})$. This extract $(20 \mathrm{~g})$ was suspended in $\mathrm{H}_{2} \mathrm{O}(1 \mathrm{~L})$ and partitioned successively with $n$-hexane $(3 \times 1 \mathrm{~L})$, EtOAc $(3 \times 1 \mathrm{~L})$, and $n$-BuOH $(3 \times 1 \mathrm{~L})$ to yield $n$-hexane-, EtOAc-, and $n$-BuOH-soluble fractions of $8.0,1.1$, and $5.2 \mathrm{~g}$, respectively. The EtOAc-soluble fraction, which inhibited HNE significantly $\left(\mathrm{IC}_{50}=40.6 \mu \mathrm{g} / \mathrm{mL}\right)$, was subjected to silica gel column chromatography $(70-230 \mathrm{mesh}, 50 \times 5.0 \mathrm{~cm})$, and eluted with a gradient solvent system consisting of $\mathrm{CH}_{2} \mathrm{Cl}_{2}-$ $\mathrm{MeOH}(50: 1 \rightarrow 4: 1)$ to generate five fractions (E1-E5). These five fractions inhibited $\mathrm{HNE}$ by $72,68,52,43$, and $22 \%$, respectively, at $100 \mu \mathrm{g} / \mathrm{mL}$. Thus, fractions E1 and E2 that significantly inhibited HNE were investigated extensively.

Fraction E1 $(150 \mathrm{mg})$ was applied to a YMC RP-18 column $(50 \times 3.5 \mathrm{~cm})$, and eluted with a $\mathrm{MeOH}-\mathrm{H}_{2} \mathrm{O}$ gradient solvent system $(3: 7 \rightarrow 5: 5)$, yielding two subfractions (E1.1-E1.2). These fractions were further purified by preparative reverse phase (RP)-HPLC [Gilson TRILUTION system; YMC-pack Pro $\mathrm{C} 18\left(250 \times 10 \mathrm{~mm}\right.$, i.d.) column; $\mathrm{MeOH}-\mathrm{H}_{2} \mathrm{O}(60: 40$, $\mathrm{v} / \mathrm{v})$; UV detection, $254 \mathrm{~nm}$; flow rate $2.5 \mathrm{~mL} / \mathrm{min}$ ] to afford $4\left(0.8 \mathrm{mg}, t_{\mathrm{R}}=30.2 \mathrm{~min}\right)$ and $\mathbf{5}\left(1.8 \mathrm{mg}, t_{\mathrm{R}}=32.0 \mathrm{~min}\right)$ from E1.1 and $1\left(1.0 \mathrm{mg}, t_{\mathrm{R}}=34.0 \mathrm{~min}\right)$ from E1.2. Compounds $2(5 \mathrm{mg}$, $\left.t_{\mathrm{R}}=31.0 \mathrm{~min}\right)$ and $3\left(7 \mathrm{mg}, t_{\mathrm{R}}=37.4 \mathrm{~min}\right)$ were isolated from E2 $(210 \mathrm{mg})$ using preparative RP-HPLC [Gilson TRILUTION system; YMC-pack Pro C18 $(250 \times 10 \mathrm{~mm}$, i.d.) column; $\mathrm{MeOH}-\mathrm{H}_{2} \mathrm{O}(40: 60, \mathrm{v} / \mathrm{v})$; UV detection, $254 \mathrm{~nm}$; flow rate $2.5 \mathrm{~mL} / \mathrm{min}$ ].

Ramarin A (1): Colorless oil. $[\alpha]_{\mathrm{D}}^{25}+180^{\circ}(c=0.1, \mathrm{MeOH})$. UV (MeOH) $\lambda_{\text {max }}$ nm $(\log \varepsilon): 239$ (3.95). IR (KBr) $v_{\max } \mathrm{cm}^{-1}$ : $3420,1665,1650$. EI-MS $m / z$ (rel. int.): $250[\mathrm{M}]^{+}(10), 232$ (66), 217 (100), 201 (26), 175 (49). HR-EI-MS m/z: 250.1567 $[\mathrm{M}]^{+}$(Calcd for $\left.\mathrm{C}_{15} \mathrm{H}_{22} \mathrm{O}_{3}: 250.1569\right)$. ${ }^{1} \mathrm{H}$ - and ${ }^{13} \mathrm{C}-\mathrm{NMR}$ data, see Table 1.

Ramarin B (2): Colorless oil. $[\alpha]_{\mathrm{D}}^{25}+93^{\circ}(c=0.1, \mathrm{MeOH})$. $\mathrm{UV}(\mathrm{MeOH}) \lambda_{\max } \mathrm{nm}(\log \varepsilon): 237$ (3.92). IR (KBr) $v_{\max } \mathrm{cm}^{-1}$ : 3410, 1662, 1654. EI-MS $\mathrm{m} / \mathrm{z}$ (rel. int.): $234[\mathrm{M}]^{+}$(30), 219 (35), 203 (55), 164 (100), 149 (60),121 (70), 91 (65). HR-EI-MS $\mathrm{m} / \mathrm{z}: 234.1622[\mathrm{M}]^{+}$(Calcd for $\left.\mathrm{C}_{15} \mathrm{H}_{22} \mathrm{O}_{2}: 234.1620\right)$ ). ${ }^{1} \mathrm{H}-$ and ${ }^{13} \mathrm{C}-\mathrm{NMR}$ data, see Table 1.

HNE Inhibitory Assay HNE inhibitory activity was evaluated according to a previously described procedure. ${ }^{13)}$ Briefly, $100 \mu \mathrm{L}$ reactions containing $10 \mathrm{~mm}$ Tris- $\mathrm{HCl}$ buffer $(\mathrm{pH} 7.5)$, $1.4 \mathrm{~mm}$ MeO-Suc-Ala-Ala-Pro-Val-p-nitroanilide, $0.18 \mathrm{U}$ HNE (EC 3.4.21.37, from Serva, Heidelberg, Germany), and various concentrations of sample were incubated in the wells of a 96-well plate for $2 \mathrm{~h}$ at $37^{\circ} \mathrm{C}$ in the dark. Each reaction was stopped by the addition of $100 \mu \mathrm{L}$ soybean trypsin inhibitor $(0.2 \mathrm{mg} / \mathrm{mL})$, and the absorbance at $405 \mathrm{~nm}$ was immediately measured using a microplate reader. EGCG was used as a positive control.

Acknowledgments This study was supported by a Grant from the Technology/R\&D Project, Small and Medium Business Administration, Republic of Korea (SMBA2014-S2211621). The NMR and MS experiments were performed by the Korea Basic Science Institute (KBSI).

Conflict of Interest The authors declare no conflict of interest.

\section{References}

1) Steinbrecher T., Hrenn A., Dormann K. L., Merfort I., Labahn A., Bioorg. Med. Chem., 16, 2385-2390 (2008).

2) Bissett D. L., Hannon D. P., Orr T. V., Photochem. Photobiol., 46, 367-378 (1987).

3) Lorenzen K., Anke T., Curr. Org. Chem., 2, 329-364 (1998).

4) Lee I. K., Jung J. Y., Kim Y. H., Yun B. S., J. Antibiot., 63, 263-266 (2010).

5) Lee I. K., Yun B. S., J. Antibiot., 64, 349-359 (2011).

6) Ramesh C., Pattar M. G., Pharmacognosy Res., 2, 107-112 (2010).

7) Yoo I. S., Woo M. S., Choi E. C., Kim B. K., Kor. J. Mycol., 10, 165-171 (1982).

8) Ginterová A., Janotková O., Findová E., Folia Microbiol., 26, 133136 (1981).

9) Zhang R., Tian G., Zhao Y., Zhao L., Wang H., Gong Z., Ng T. B., J. Basic Microbiol., Epub ahead of print (2014).

10) Kanokmedhakul S., Lekphrom R., Kanokmedhakul K., Hahnvajanawong C., Bua-art S., Saksirirat W., Prabpai S., Kongsaeree P., Tetrahedron, 68, 8261-8266 (2012).

11) Zubía E., Ortega M. J., Carballo J. L., J. Nat. Prod., 71, 2004-2010 (2008).

12) Asakawa Y., Yamamura A., Waki T., Takemoto T., Phytochemistry, 19, 603-607 (1980).

13) Kim Y. H., Ryoo I. J., Choo S. J., Xu G. H., Lee S., Seok S. J., Bae K., Yoo I. D., J. Microbiol. Biotechnol., 19, 1139-1141 (2009).

14) Itokawa H., Masuyama K., Morita H., Takeya K., Chem. Pharm. Bull., 41, 1183-1184 (1993).

15) Rodríguez B., de la Torre M. C., Simoes F., Batista O., Nascimento J., Duarte A., Mayer R., Phytochemistry, 38, 905-907 (1995).

16) Tada A., Kanamaru A., Katagiri T., Jpn. Kokai Tokkyo Koho, 2000-026235 A2 (2000).

17) Tada A., Kanamaru A., Katagiri T., Jpn. Kokai Tokkyo Koho, 2000-053523 A2 (2000). 